\title{
Not only pigeons: avian olfactory navigation studied by satellite telemetry
}

FRANCESCO BONADONNA $^{1, *}$ and ANNA GAGLIARDO ${ }^{2}$

${ }^{1}$ CEFE, CNRS, University of Montpellier, EPHE, IRD, University Paul Valéry Montpellier 3, Montpellier, France

${ }^{2}$ Department of Biology, University of Pisa, Pisa, Italy

The olfactory navigation hypothesis proposed to explain homing pigeon navigation predicts that birds learn the association of wind directions and wind-borne odours at home, and once displaced, determine the home direction on the basis of local environmental odours at the release site. This hypothesis was proposed on the basis of two kinds of empirical observations: (i) pigeons develop navigational abilities only if exposed to winds at the home loft, (ii) anosmic pigeons displaced to unfamiliar sites are unable to home. Soon after the discovery of the role of olfaction in pigeon navigation about 50 years ago, olfactory navigation became a subject of hot scientific debate. Until the beginning of the GPS era, the large body of evidence in support of olfactory navigation in pigeons, swifts and starlings consisted mainly of vanishing bearings and homing performance data. The use of GPS, allowing the observation of the pigeons' behaviour en route provided further compelling evidence of the role of olfactory cues in pigeon navigation. The development of wildlife telemetry in the past two decades produced strong evidence about the use of olfactory cues, also in navigation of some species of wild birds. Wild birds artificially displaced both during 
migration, or during incubation showed impaired capacities to compensate displacements only if deprived of their sense of smell. Contrariwise, satellite telemetry failed to find any empirical validation for the existence of a navigational map based on magnetic cues in the tested species. In spite of the fact that the nature of the olfactory map in wild birds has not yet been elucidated, the development and miniaturisation of satellite technology will hopefully allow us in the near future to investigate in detail the features of the olfactory map found in some wild species, and to clarify the sensory basis of navigation in free-ranging small passerines.

KEY WORDS: navigation, orientation, olfaction, seabirds, passerines, homing pigeons, satellite telemetry.

*Corresponding author: Francesco Bonadonna, CEFE-CNRS, 1919 Route de Mende, 34293

Montpellier, France (E-mail: francesco.bonadonna@cefe.cnrs.fr).

Running head: Not only pigeons: avian olfactory navigation 


\section{HISTORY OF THE DISCOVERY OF THE ROLE OF OLFACTION IN PIGEON}

\section{NAVIGATION}

In the early 1970s, the discovery of the role of olfaction in pigeons' homing surprised scholars of avian navigation, and raised perhaps one of the fiercest debates in the field of animal behaviour. As often happens, this discovery was due to the intuition of a researcher, who looked afresh at the previously-reported evidence on the subject. This researcher was Floriano Papi, who guessed the possible involvement of olfaction in birds' navigation by reading a study by Hans G. Wallraff on the role of the view of the horizon on the development of pigeons' navigational abilities (Wallraff 1966, 1970). By comparing initial orientation of pigeons raised in different kinds of shielded aviaries, Wallraff discovered an unexpected role for atmospheric cues in the ontogenesis of the pigeons' navigational map (Wallraff 1970). Pigeons raised in aviaries surrounded by glass screens, both allowing the view of the horizon and screening the wind flow inside the aviary, displayed impaired homeward orientation. By contrast, pigeons raised in aviaries surrounded by louvre screens, both preventing the view of the surroundings and allowing the exposure of the birds to the winds, oriented towards home. The conclusion of these studies, that an undefined atmospheric factor was involved in the development of pigeons' navigational abilities, triggered Papi's idea to test the role of olfaction in pigeon navigation. Pigeons whose olfactory nerves had been sectioned released at an unfamiliar location displayed a dramatic impairment at homing, significantly different to that of unimpaired sham controls (Papi et al. 1971). Taking into account that prerequisites for unimpaired navigation in pigeons seemed to be both the winds blowing at the home loft and an intact olfactory system, Papi proposed the so-called "olfactory navigation hypothesis" (Papi et al. 1972), explaining how birds could learn a map of distant areas without directly exploring them. The olfactory navigation hypothesis predicted that during a learning phase at home, pigeons are able to learn the directions of the prevailing winds together with olfactory 
information carried by these winds, so to build up a sort of olfactory map of wide areas around the home loft. Once at the release site, pigeons are able to determine the direction of displacement by recognising the prevalent local odours and recalling the direction of the wind that carried those odours to the home area. In its original formulation the olfactory map proposed by Papi was a sort of mosaic map, as wide areas around the pigeons' home were supposed to be characterised by specific and different odours. According to Papi's view such a map could allow pigeons to navigate within relatively short distance (about one hundred kilometres). Only later, Wallraff proposed that the olfactory map was likely to be based on odour gradients allowing navigation over longer distances. In his view, the ratio of gradients of volatile organic compounds (VOCs) aligned in different directions could allow the birds to determine the direction of displacement. By testing homing pigeons at increasing distances from the loft, Wallraff found that their initial orientation performances in Germany were poorer at short distances from home, and more accurate at larger distances, within a range of $300 \mathrm{~km}$ and even up to $700 \mathrm{~km}$ (Wallraff 1981). This is consistent with the view that at short distances from the loft the VOC distribution might be similar to that of the home area (Zannoni et al. 2020), and unlikely to provide accurate spatial information. The existence of fairly stable spatial gradients of VOCs was reported by Wallraff and Andreae (2000), who analysed samples of air collected at 96 sites regularly distributed within $200 \mathrm{~km}$ around an experimental pigeon loft near Würzburg (Germany). Subsequent simulation experiments showed that stable ratios of at least three VOCs distributed along different directions, rather than their absolute concentrations, are sufficient to provide virtual pigeons information on the direction of displacement. Interestingly, the level of homeward orientation of the virtual pigeons orienting on the basis of those VOC ratios was comparable to that experimentally observed (Wallraff 2000). 


\section{EXPERIMENTAL EVIDENCE FOR OLFACTORY NAVIGATION IN HOMING \\ PIGEONS COLLECTED WITH TRADITIONAL METHODS, AND DEBATES ON PIGEON NAVIGATION}

Before the satellite tracking era, the most used method to study pigeon navigation was recording the direction at which a displaced pigeon vanished from the view of an observer using powerful binoculars (Matthews 1951). Therefore, vanishing bearing distributions represent the orientation of the birds at about $2 \mathrm{~km}$ from the release points. Beside their ability to navigate, pigeons' initial orientation turned out to be potentially affected by a number of factors (Wallraff 2005), such as the previous experience of the birds, local features of the release site biasing the birds' orientation, and the preferred compass direction (PCD) of the tested group of birds (Wallraff 1978; Ioalè 1995). In some cases, these factors might confound the interpretation of initial orientation data (Papi 1990; Wallraff 2005) for assessing the actual pigeons' ability to navigate. However, the comparison between the homing performances of manipulated and unmanipulated pigeons provided unmistakable information: the disruption of navigational abilities following an experimental manipulation was evident if the pigeons were impaired at homing. Therefore, initial orientation data can be reliably interpreted while testing birds' navigation only if considered together with their homing performances.

Despite the lack of information on the route followed by pigeons to home or to get away from it, the contribution to the knowledge of pigeon navigation given by experiments performed with traditional methods was invaluable. The large body of both vanishing bearing and homing performance data collected over more than four decades for testing the role of olfactory cues in pigeon navigation contributed to the clarification of important features of the odour-based navigational mechanism (Wallraff 2005). 
The navigational map is generally learned by pigeons within the first 3 months after fledging. With this respect, the specific role of the winds blowing within the home area in the ontogenesis of the navigational map of homing pigeons observed by Wallraff (1970) has also been confirmed by subsequent experiments: a total screening of the winds consistently produced an impairment in the development of navigational abilities of young birds (Gagliardo et al. 2001; Odetti et al. 2003). However, once the map has been learned, it is continuously updated. In fact, pigeons kept in an aviary provided with clockwise and counterclockwise wind deflectors displayed a consistent rotation in their initial orientation (Baldaccini et al. 1975; Fiaschi et al. 1981). In the same way pigeons subjected to inversion of the winds displayed an inverted initial orientation (Ioalè et al. 1978; Ioalè 1980).

The importance of olfactory information picked up at the release site was stressed by the socalled "false release site" experiments. In this kind of experiment, pigeons were displaced inside air-tight containers ventilated by purified air. A group of pigeons was transported to a false release site where the birds were exposed to environmental local air. Then, these birds were transported to the real release site in purified air condition and then released after nasal anaesthesia. These pigeons turned out to be fooled by the treatment, so that they oriented as if they were released at the false release site (Benvenuti \& Wallraff 1985).

Direct evidence that olfaction was specifically involved in pigeon navigation came from the consistent impaired homing performance of the anosmic birds when displaced to unfamiliar locations. Soon after the discovery of the role of olfaction in pigeon navigation, the first concern by Papi and his collaborators was to make sure that the impairment of the olfactory deprived pigeons was not due to a non-specific effect of the treatment. Two kinds of observations spoke against a non-specific effect of anosmia in producing impaired navigation. The first is that two groups of pigeons subjected to the same two manipulations, section of 
one olfactory nerve and application of a plug to one nostril, produced different effects depending whether the section of the nerve was contra- or ipsi-lateral to the application of the plug (Papi et al. 1972). In the first case the birds were totally deprived of their sense of smell and their navigational performances were totally disrupted, while in the second case they could still use one nostril displaying more proficient homeward orientation and homing abilities than the birds released in total anosmia. Non-specific effects of anosmia were also disproved by unimpaired orientation and homing of anosmic pigeons displaced to familiar sites (Benvenuti et al. 1973), where birds were likely to rely on familiar visual cues for homing (Wallraff \& Neumann 1989). However, the navigational role of familiar visual cues in homing pigeon was contested by some authors (Schmidt-Koenig 1979; Wiltschko 1991, 1996; Wiltschko \& Wiltschko 1998; Wiltschko et al. 2005) on the basis of the evidence that wearing frosted lenses did not prevent the pigeons from homing (Schmidt-Koenig \& Walcott 1978), and that clock-shifted pigeons released at familiar sites displayed a deflection in their initial orientation, as if the directional information offered by the familiar landscape were ignored (Füller et al. 1983; Luschi \& Dall'Antonia 1993; Wiltschko et al. 2005).

Despite the accumulation of evidence in favour of the role of olfactory cues in pigeon navigation, the plausibility and the existence of olfactory navigation has been subject of a hot debate for decades. It is worth noting that for the reasons mentioned above, the debate on olfactory navigation became somehow linked to the debate on whether familiar visual landmarks could provide navigational information to the pigeons (Wiltschko 1996).

When it became clear that the navigational impairment of anosmic pigeons was a robust and reproducible effect, the detractors of olfactory navigation tried to find alternative explanations to the phenomenon other than the navigational role of olfactory cues. When the ophthalmic branch of the trigeminal nerve was hypothesised to be part of a magnetoreception system in 
the birds' upper beak (Fleissner et al. 2003), the olfactory navigation hypothesis was subjected to a new challenge. It was argued that the navigational impairment observed after olfactory manipulations was likely to be due to an accidental damage of the trigeminally mediated magnetoreceptor, involved in the supposed magnetic navigation in homing pigeons (Mora et al. 2004), although it was well known that no magnetic manipulation ever affected pigeons' homing success (see Wallraff 2005 for references). Three experiments, however, ruled out the involvement of the ophthalmic branch of the trigeminal nerve in pigeon navigation and in the same time provided further support to olfactory navigation (Gagliardo et al. 2006, 2008, 2009).

More recently, the specific role of olfactory cues in pigeon navigation was contested by the proponent of the so called "olfactory activation hypothesis" (Jorge et al. 2010). According to this hypothesis, anosmia has a disruptive effect on pigeon homing because the pigeons' brain needs to be activated by olfactory cues for using a navigational mechanism based on cues other than odours (magnetic cues, infrasounds). In this view environmental local odours at the release site do not provide any spatial information, as even non-sense artificial odours are able to trigger a successful navigational response. This hypothesis was supported by vanishing bearings data showing that pigeons stimulated with artificial non-sense odours during transportation and at a false release site, and then released after nasal anaesthesia, oriented similarly to pigeons treated in the same way but exposed to environmental odours. Disrupted navigational performances were obtained following transportation in purified air transportation and anaesthesia of the olfactory mucosa before release. Further on, the “olfactory activation hypothesis" was contradicted by GPS-tracking data (see below). 
Before the GPS era started, several attempts to document pigeons' flight paths beyond their vanishing directions were performed. Well before the discovery of the role of olfaction in navigation, Papi and Pardi followed pigeons released in the open sea using a ship's radar (Papi \& Pardi 1968). The birds were provided with a radar target, consisting of a pyramidal frame covered with aluminium, hanging from the pigeon's leg. Other studies employed radiotracking methods to extend the observation of the orientation beyond the vanishing points (Teyssèdre 1986; Bingman \& Mench 1990), but the dream of recording the flight of the pigeons along their entire route could seldom be fulfilled, as at that time the only way to do this was to follow the pigeons with an airplane or helicopter (Griffin 1952a; Hitchcock 1952, 1955; Michener \& Walcott 1966; Schmidt-Koenig \& Walcott 1978). In one of these cases, the tracks of pigeons exposed to deflected winds inside their aviaries were documented by following the pigeons with a helicopter (Fiaschi et al. 1981). This study provided a direct observation of the persistent deflection of the pigeons' path, consistent to the exposure to deflected winds at home. Further attempts to study the behaviour of the pigeons en route during homing were performed after the development of a route recorder logger (Bramanti et al. 1988), which allowed a rough reconstruction of the path followed by a pigeon from its release point to home, through the recording of the compass directions maintained by the bird during its flight at a theoretical mean speed. This method was mainly employed to study how pigeons reacted to familiar geographical features beyond the release site. This primitive tracking method offered the first chance to document, although not precisely, the behaviour en route of anosmic pigeons. After having been exposed either to the release site air (control group) or to the air of a false release site located in the opposite direction from home with respect to the true release site, the birds were made temporarily anosmic prior release by spraying their olfactory mucosa with a local anaesthetic. The orientation of the initial part of the reconstructed tracks, when the anaesthetic was likely to be still effective, was consistent to 
the pigeons' reliance on local environmental odours prior release for determining the home direction (Dall'Antonia et al. 1999).

The miniaturisation of the GPS loggers at the beginning of the 2000s offered the opportunity to observe and study the homing behaviour of pigeons from the release point up to their home. As the loggers needed to be recovered to download the birds' tracks, they were particularly suitable for studying pigeon navigation over familiar areas (see Guilford \& Biro 2014 for references). By contrast, for many years GPS-tracking methods were not applied to test olfactory navigation. The reason is easy to understand. As anosmic pigeons were unlikely to home from unfamiliar locations, the necessity to recover the logger to obtain positional data made GPS loggers unsuitable for documenting impaired navigation abilities. However, in 2011 the first GPS tracking experiment reporting performances of birds made temporarily anosmic by nasal anaesthesia was reported (Gagliardo et al. 2011). Although GPS loggers were used, the devices emitted a signal that allowed their localisation to be remotely downloaded. Flying in a Cessna light aircraft, one of the co-authors, Martin Wikelski, localised and downloaded the tracks of birds unable to home. This experiment aimed at testing the role of olfactory stimuli in pigeon navigation. The question addressed was whether olfactory stimuli specifically provided spatial information, or had an activational role for the brain, as predicted by the olfactory activation hypothesis. The birds were kept in air-tight containers artificially ventilated, so to control the olfactory stimuli the birds were exposed to, both during transportation and at the release site. The container of one group of pigeons was ventilated with local environmental air, while the containers of the other two groups of birds were ventilated with air purified with a charcoal filter. Importantly, one of the two groups transported and kept in purified air also received olfactory stimulation with artificial odours. The pigeons belonging to the three experimental groups received anaesthesia of their olfactory mucosa prior to release so that their behaviour was attributable to the olfactory 
stimuli experienced inside the air-tight container. If olfactory stimuli acted merely as "activators" also the group stimulated with artificial non-sense odours was expected to orient homeward, similarly to the birds stimulated with environmental odours. The analysis of the tracks recorded within $1 \mathrm{hr}$ from release, when the anaesthesia was likely to be still effective, showed a dramatic impairment of the navigational performances of the pigeons stimulated with artificial odours. Consistent findings were reported in a recent similar experiment in which birds either exposed to local environmental odours or stimulated with artificial odours were made anosmic prior to release using a zinc-sulphate nasal washing that, inducing necrosis of the olfactory neurons, produces a longer lasting anosmia (Gagliardo et al. 2018). Again, olfactory stimulation with artificial non-sense odours was unable to produce homeward orientation in pigeons. Interestingly, most of these birds displayed disoriented pattern of movement, which is in open contradiction to an activational role of olfactory stimuli. By contrast, pigeons exposed to local environmental air inside the air-tight container before being made anosmic, were still able to orient homeward, although most of them were unable to reach home (Gagliardo et al. 2018). Tracking data have confirmed that pigeons rely on local environmental odours at the release site for determining the direction of displacement, and that for a successful homing, pigeons need to consult their olfactory map on their way (Gagliardo et al. 2016). Local environmental odours might encourage pigeons in pursuing in the direction assumed at the release site, or might determine an adjustment of their orientation (Gagliardo et al. 2018).

The study of the use of familiar visual landmarks in homing pigeons grew with the use of GPS loggers, mainly thanks to Tim Guilford and collaborators, who critically contributed to the understanding of route fidelity in homing pigeons (Guilford \& Biro 2014). Nevertheless, until recently no GPS tracking data on the navigational role of familiar visual landmarks in anosmic pigeons were available. As briefly mentioned above, the use by homing pigeons of a 
familiar visual landmark-based map for navigation was questioned by some authors. Importantly, whether or not unimpaired homing performances of anosmic pigeons from familiar sites are due to the use of familiar visual cues has important implication for the debate on olfactory navigation (Wiltschko 1996; Walcott et al. 2018). The ability of anosmic pigeons to extract navigational information from a familiar landscape speaks against a nonspecific effect of anosmia treatment. Perhaps more importantly, the impaired and unimpaired homing abilities of anosmic pigeons released at unfamiliar and familiar locations, respectively, suggest that the multi-cue navigational system proposed to explain pigeon navigation (Walcott 1996; Walcott et al. 2018) is exclusively composed of olfactory and familiar visual landmarks (Gagliardo 2013).

Recently, a GPS-tracking study showed that after one single release from a site pigeons are able to rely on previously over-flown landscape elements, and that olfactory deprived pigeons are more inclined to do so (Gagliardo et al. 2020). This study suggested that the availability of olfactory cues can affect navigational strategies adopted by pigeons. In comparison to their smelling companions, the anosmic birds were more likely to retrace the previously followed route (pilotage strategy) even if inefficient, rather than relying on a map and compass strategy that would lead them more directly home.

\section{OLFACTORY NAVIGATION FROM THE MODEL SPECIES TO WILD BIRDS}

Many birds display true navigation abilities, that is the ability to find their way to a goal starting from a unknown location (Griffin 1952b). Homing pigeons are a domestic breed selected by humans to home to their loft after artificial displacements. Wild species can be accidentally displaced by atmospheric events to unknown places, or, like seabirds during their wandering trips, they can find themselves in unknown areas void of landmarks. During 
breeding, central place foragers need to find foraging areas and then home back efficiently to the nest. When a foraging bird is displaced its motivation is similar to that of a displaced homing pigeon: pinpointing its nest and homing. A bird unable to navigate is expected to show disoriented movements or to orient in an unpredictable direction different from the home direction. A different behaviour is expected in birds navigating after a displacement during migration. Migratory species need to accomplish long trips between breeding and wintering sites. When a migrating bird is displaced, it is expected to correct for displacement to reach either the migratory corridor, or the breeding or wintering site. Migrants on their first flight are supposed to use an innate vector navigation mechanism and are thus unable to correct for displacement (Perdeck 1958; Berthold 1991; but see Thorup et al. 2020), while experienced migrants, exposed to environmental clues and cues during their previous migratory trips, developed navigational abilities (Thorup et al. 2007). Which are the environmental cues used by wild species to navigate?

In 2004, Hans G. Wallraff wrote "Which role does olfactory navigation play in the birds' natural life? It is extremely unlikely that homing pigeons have a navigation mechanism that is unique among birds" (Wallraff 2004). As at that time only two experiments had suggested olfactory navigation in non-domesticated birds, Wallraff was visionarily anticipating what would be found by tracking studies in the following years in other species. In the two older experiments swifts (Apus apus), and starlings (Sturnus vulgaris) were artificially displaced during their incubation period, so that the birds were motivated to return to their nests. In swifts Fiaschi and co-workers (Fiaschi et al. 1974) applied a double treatment to the birds consisting of the sectioning of one olfactory nerve and the occlusion of one nostril: for control birds both treatments were ipsilateral, while for the experimental birds the plugged nostril was contralateral to the intact olfactory nerve. Fifteen out of 20 control birds and three out of 23 experimental birds homed. Interestingly, these three experimental birds had lost their nose 
plugs. Wallraff and collaborators (Wallraff et al. 1995) showed that starlings subjected to bilateral olfactory nerve section took longer to home when displaced at a distance of 30-60 $\mathrm{km}$, where the area was likely to be familiar to them. However, when displaced beyond 120 $\mathrm{km}$ return rates of anosmic starlings were dramatically reduced. After these early studies, the possible involvement of olfaction in wild birds' navigation was neglected for a long time.

More recently, two other passerine birds have been tested during migration. In a first experiment, catbirds (Dumetella carolinensis) were followed by radiotracking for approximately $100 \mathrm{~km}$, and authors highlighted, with sensory manipulation, the essential role of olfaction in adults' migration. Displaced anosmic adult catbirds maintained the speciesspecific inherited migratory direction similarly to the young catbirds at their first flight. This suggested that olfaction plays a role in adult catbirds' navigation. Interestingly, magnetic manipulation did not affect the ability of adult catbirds to correct for displacement (Holland et al. 2009). Conversely, years later, Kishkinev and collaborators working on adults of Eurasian reed warblers (Acrocephalus scirpaceus), produced evidence supporting an opposing conclusion. Reed warblers, tested in Emlen's funnels and virtually magnetically displaced, were shown to correct the displacement (Kishkinev et al. 2015), suggesting the use of magnetic cues for navigation. When tested in the field, with an actual displacement from their migratory route and sensory manipulation, both anosmic and control reed warblers compensated the artificial displacement (Kishkinev et al. 2020). The authors concluded that this species does not rely on olfactory cues for navigation. However, it must be considered that reed warblers were radio-tracked only for 3-5 km, which corresponds to an initial orientation decision. From homing pigeon experiments, we know that initial orientation decision does not always reflect navigational abilities of displaced birds, and that for this reason the analysis of their homing success is required to infer robust conclusions. Since the homing success of migrating birds can only be assessed by tracking them until they reach 
their migratory corridor or their final destination, initial orientation at a short distance from the release site loses most of its predictive power. In a similar experiment, also based only on initial decision at a short distance from the release site, white-throated sparrows (Zonotrichia albicollis) seemed unable to compensate for displacement regardless of the sensory manipulation to which they were subjected (Kishkinev et al. 2016). In our opinion, birds might be initially attracted by some landscape features, and take the definitive orientation at further distance from the release site, as for instance was observed in experimentally displaced gulls (Wikelski et al. 2015). Even if this reasoning can also be applied for the experiment on catbirds (Holland et al. 2009), it should be considered that catbirds were tracked up to $100 \mathrm{~km}$, well beyond their initial bearings. For this reason, the catbird experiment provided at least a hint for the use of olfaction in navigation, while the results on reed warblers and white-throated sparrows were essentially inconclusive (Kishkinev et al. 2016).

To date, field investigations on free-ranging small passerines were limited to radio-tracking, because of the size and weight of satellite telemetry devices. Awaiting the development of new lightweight tools in this field to clarify the sensory basis of navigation in passerines (Guilford et al. 2011), larger migrants have been tested during migration. Lesser black-backed gulls, (Larus fuscus fuscus) nesting in Finland and Russia and migrating from breeding sites to the Nile Delta and to Lake Victoria in sub-Saharan Africa, were subjected to sensory manipulation in order to test the role of olfactory and magnetic cues in their ability to compensate for displacement. To test the role of olfactory cues a group of birds had their olfactory nerves sectioned, while to test the role of magnetic cues a group of birds was subjected to section of the ophthalmic branch of their trigeminal nerve. Although both the involvement of the trigeminal system in pigeon navigation was disproved by displacement experiments (Gagliardo et al. 2006, 2008, 2009) and the existence of a magnetic receptor in 
the pigeon upper beak was challenged by an accurate histological study (Treiber et al. 2012), the involvement of the ophthalmic branch of the trigeminal nerve in migratory species navigation found support in cage orientation studies (Kishkinev et al. 2013).

Sensory manipulated lesser black backed gulls and control gulls were displaced and tracked before the beginning of their migration from their breeding grounds, central Finland and White Sea area in Russia, to Helgoland (1250 km SW) and Kazan (1301 km SE), respectively. Authors also equipped with GPS non-displaced birds from the two breeding sites, to obtain information about the migratory corridors of the two populations of lesser blacked back gulls. Whether or not the ophthalmic branch of the trigeminal nerve carries magnetic information to the brain is still controversial (Treiber et al. 2012; Kishkinev et al. 2013). However, the gulls subjected to trigeminal section were able to compensate for displacement, as well as the intact control birds, suggesting that the trigeminal system is not involved in lesser black backed gulls' navigation. By contrast, birds subjected to olfactory nerve section showed different behaviour according to the population tested. Anosmic birds displaced from Finland to Helgoland were impaired in approaching their migratory corridor while anosmic birds displaced from Russia to Kazan were able to correct for displacement. Interestingly, observing natural migrating corridors obtained from non-displaced birds, the Kazan area turned out to be within the natural migratory route of the Russian population of lesser black-backed gulls (Wikelski et al. 2015). Therefore, lesser black-backed gulls seemed to be able to correct for displacement by using olfactory cues over unfamiliar areas and by using familiar visual cues within previously experienced areas (Wikelski et al. 2015).

Among wild birds the development of satellite telemetry brought compelling evidence of olfactory navigation in seabirds, particularly in petrels. With his foresight this was also predicted by Wallraff when he wrote about olfactory navigation: "Procellariiform seabirds 
(albatrosses, petrels) would be of particular interest for several reasons" (Wallraff 2004). During the breeding period, pelagic seabirds are forced to commute between their breeding colony and distant foraging grounds. Like migrating birds, they are able to travel large distances, and very old homing experiments early suggested the navigational abilities of some species (Griffin 1940; Matthews 1953, 1964; Kenyon \& Rice 1958; Billings 1968). To accomplish their astonishing flights, seabirds should dispose of navigation capacities similar to those of migrants, and present the particular interesting example of animals that are challenged by navigation in an apparently featureless environment (Bonadonna et al. 2003a). Individuals travel over vast stretches of open ocean without landmarks, and in areas where several magnetic parameters are not suitable for a magnetic navigational map (Åkesson \& Alerstam 1998; Boström et al. 2012).

It is widely believed that birds use the Earth's magnetic field to navigate, especially in open sea. Therefore, quite early, specific experiments to test the existence of a magnetic-based navigation system were performed by interfering with the perception of the magnetic field, a technique suggested by Keeton (1971). Scopoli's shearwaters (Calonectris diomedea) carrying magnets on both wings and head and released 160-900 km away from their Mediterranean breeding colony homed with the same success as the control birds (Massa et al. 1991). In oceans, displaced white-chinned petrels (Procellaria aequinoctialis) with mobile magnets on their heads, and equipped with satellite transmitters, homed almost in a straight line from $300 \mathrm{~km}$ (Benhamou et al. 2003). Similarly, magnet-carrying black-browed albatrosses, Diomedea melanophris, wandering albatrosses, Diomedea exulans, and waved albatrosses, Phoebastria irrorata, during spontaneous foraging trips followed by satellite telemetry, showed no differences in trip duration or mass gain suggesting that magnetic information is not necessary for navigation (Bonadonna et al. 2003b, 2005; Mouritsen et al. 2003). A recent correlational study on Manx's shearwaters (Puffinus puffinus) suggested the 
existence of magnetic imprinting on the natal site's magnetic inclination, used by birds to choose their breeding colony at their first breeding attempt (Wynn et al. 2020). Rightly, authors suggested that experimental tests are needed to verify the results of this correlational study. Indeed, if Manx's shearwaters are able to determine the latitude of the colony location one should expect anosmic individuals displaced in open ocean to be unimpaired in returning at least to the same latitude of the breeding colony. It is worth considering that anosmic shearwaters of close species (Cory's and Scopoli's shearwaters) turned out to be unable to do so (Gagliardo et al. 2013; Pollonara et al. 2015).

Strong expectations about the use of the olfactory navigation by wild birds was, and still is, fed by experiments suggesting the importance of olfactory cues in oceanic foraging trips in penguins and petrels. The idea of foraging areas having a characteristic smell, leading petrel seabirds to them, was firstly formulated by Grubb (1972). Several successive studies, floating food odours on the sea surface and counting species approaching the odour source, confirmed that some petrel species are attracted by these cues that seem to help these seabirds in orientation towards the feeding areas (review in Roper 1999). Modelling studies on foraging tracks of shearwaters (Cory's shearwaters, Scopoli's shearwaters, and Cape Verde shearwaters, C. edwardsii) also suggested that their flight pattern is compatible with olfactory guidance (Reynolds et al. 2015; Abolaffio et al. 2018).

More, some non-food odours, such as dimethyl sulphide (DMS), but only related to food, are highly attractive for some species (Nevitt et al. 1995; Nevitt \& Bonadonna 2005; Dell'Ariccia et al. 2014). Still, this behaviour is not limited to petrel species, but also seems to concern penguins and seagulls (Culik et al. 2000; Wright et al. 2011; Cunningham et al. 2017; Bouchard et al. 2019). Despite these experiments are not related to olfactory navigation, they show the critical relevance of olfaction in seabirds' biology. 
The first preliminary attempts of actual homing experiments to test olfactory orientation in seabirds were performed with short-range releases. Although these experiments were not intended to study navigation, but primarily nest pinpointing in conditions where sight or hearing could not be used, they corroborated the idea of an olfactory orientation mechanism in these seabirds. On the whole, birds made anosmic employing various techniques were not able to home to their burrow nest from 100-200 m distance (Benvenuti et al. 1993; Bonadonna et al. 2001; Bonadonna \& Bretagnolle 2002). However, when birds had access to cues alternative to olfactory ones (i.e. familiar visual landmarks), they displayed unimpaired homing ability (Dell'Ariccia \& Bonadonna 2013).

Yet again, satellite telemetry eventually allowed long distance displacements for the simultaneously testing of olfactory and magnetic mechanisms of navigation in petrels. Cory's shearwaters (Calonectris borealis), breeding in the Azores, were subjected to sensory manipulation and translocated $800 \mathrm{~km}$ east from their colony in the middle of the Atlantic Ocean. The tracks of the displaced shearwaters gave no room for doubt. The shearwaters carrying a strong mobile neodymium magnet on their head displayed linear homing path straight to the colony, similar to those of unmanipulated control birds, while the birds made anosmic with zinc sulphate nasal washing displayed long and tortuous path searching for the goal, without being able to reach it in most of the cases (Gagliardo et al. 2013). These results clearly showed that, while geomagnetic information is neither sufficient nor necessary for shearwater navigation in open ocean, olfactory cues are needed to find the breeding island. It is worth highlighting that olfactory navigation is also adopted by the twin species Scopoli's shearwater (Calonectris diomedea), to navigate in a relatively small (for their flight capacities) close sea, such as Mediterranean Sea. After displacement in open sea, away from the view of the coast, Scopoli's shearwaters with an intact sense of smell oriented homeward, while anosmic birds oriented away from home. Interestingly, the anosmic Scopoli's 
shearwaters were able to head home only after having approached the coastline (Pollonara et al. 2015), suggesting that similarly to homing pigeons, petrels can exploit familiar visual landmarks for finding their way home.

Zinc-sulphate nasal washing at the concentrations used in navigational experiments induces a degeneration of olfactory neurons, without destroying basal cells that, after several weeks, are able to regenerate the olfactory mucosa (Cancalon 1982; Benvenuti et al. 1992; Guilford et al. 1998). Due to the importance of olfaction in petrels' biology it is worth discussing the question of whether the anosmia treatment produced specific navigational impairments or impacted shearwaters' motivation to home and behaviours such as foraging and incubation. Experimental evidence excluded non-specific effects of zinc sulphate-induced anosmia on shearwaters behaviour other than navigation (Dell'Ariccia \& Bonadonna 2013; Pollonara et al. 2015; Padget et al. 2017). The study conducted by Padget and collaborators is particularly relevant in supporting a specific effect of anosmia in shearwaters' navigation (Padget et al. 2017). Spontaneous foraging trips of GPS-tracked Scopoli's shearwaters subjected to zincsulphate nasal washing showed that anosmia treatment did not have any impact on the birds' biology. Anosmic shearwaters were similar to smelling birds in terms of gain of body mass, schedule of foraging trips and motivation to home and incubate. Importantly, their orientation during the outbound trips from their colony in Minorca up to the Catalonian coast was not affected by the anosmia treatment. Interestingly, only the navigational strategy adopted during the birds' homing trip turned out to depend on their ability to smell. While smelling birds pinpointed the colony from the beginning of their journey, the anosmic birds generically oriented towards the Mallorca Archipelago and found their colony flying along the coast.

Altogether, the results on wild birds support the suggestion of Wallraff (2004), that olfactory navigation is a phenomenon not restricted to homing pigeons. Homing pigeons are domestic 
birds artificially selected by humans from the wild species rock dove (Columba livia) since ancient Egyptian times (Levi 1965). Whatever selection mechanism (natural or artificial) does not create a trait, but advantages existing traits with a frequency-dependent mechanism: the more individuals with a given trait survive and reproduce, the more the trait spreads in the population. It is unlikely that selection created the "olfactory navigation" trait in homing pigeons. It is more probable that the trait exists in different bird species, and in the rock dove this has been artificially selected and reinforced for human purposes. It is therefore plausible that olfactory navigation may be a widespread phenomenon in birds.

\section{WHICH KIND OF OLFACTORY-BASED MAP MIGHT BE PRESENT IN WILD BIRDS?}

After the discovery of the existence of an olfaction-mediated navigational mechanism, many experiments on homing pigeons contributed to outline the major features of the olfactory map, concerning both its ontogeny and use. The ontogeny of the olfactory map is based on learning the association of wind directions and windborne odours. An important feature of this map is that pigeons determine the home direction on the basis of local olfactory information at the release site. In fact, differently from an animal following an odour plume, once the home direction has been determined, pigeons assume and maintain a compass direction for several kilometres without continuously correcting the path followed. However, pigeons are able to adjust their homing flight course reorienting from time to time (Gagliardo et al. 2016, 2018). In wild birds, beyond the impaired navigation capacities in anosmic birds, we do not know how and when the map is learned, and which factors are involved in the learning process.

To date, the most compelling evidence for olfactory navigation during migration in birds comes from the displacement experiment on lesser black-backed gulls. In this case, two nonmutually exclusive hypotheses can be advocated. Along migratory journeys birds recover at 
stopover sites (Berthold \& Gwinner 2002). During their permanence in these sites, birds might learn the patterns of the wind and associate them with windborne odours as well as homing pigeons do at the loft site. However, Safi and collaborators (Safi et al. 2016) advanced the hypothesis that correction for displacement in lesser black-backed gulls might be eased by an odour plume originating from the migration corridor. This hypothesis is corroborated by the fact that seabirds are able to approach an experimental odorous patch at sea flying upwind (Nevitt et al. 1995; Dell'Ariccia et al. 2014; Bouchard et al. 2019). The use of an odour plume is not navigation in strict sense, but a taxis that might integrate a navigational map mechanism in birds.

In pelagic seabirds one can also hypothesise two non-mutually exclusive mechanisms to acquire the olfactory navigation. One would be similar to that found in homing pigeons: once fledged, they remain in the surroundings of the natal area and learn to associate wind directions and windborne odours originating from distant areas. The other one would be the development of an olfactory landscape, learned by direct experience. During their wandering over the oceans, birds might learn the spatial distributions of olfactory patches and gradients originating from islands, coasts, waterfronts, sea-mountains, areas rich in plankton, so to build an olfactory topography. According to the characteristic behaviour of the fledgling of a given species (i.e. whether the bird remains in the surrounding of the breeding island for several weeks, or flies immediately away from it), one or the other mechanism might be likely.

The difficulty of developing experimental protocols in wild species has strongly limited the possible studies into the mechanisms by which birds navigate. However, implementation of satellite telemetry in the past two decades allowed new experiments in support of olfactory navigation both in homing pigeons and wild birds to be performed (Gagliardo et al. 2011, 2013, 2016, 2018; Pollonara et al. 2015; Wikelski et al. 2015; Padget et al. 2017). GPS 
loggers confirmed in the model species the findings obtained with traditional methods and added new evidence; in wild birds GPS and Argos transmitters showed that olfactory navigation definitely exists in some species. Satellite telemetry also failed to find any validation for magnetic navigation. Unfortunately, the present size of the devices means that they are not yet suitable for small passerines, and we demonstrably lack for satellite tracking evidence in those species. We hope that miniaturisation and improvement in the efficiency of tracking devices will soon allow the study of the sensory basis of navigation in small passerines, widening our knowledge of these extraordinary migrants.

\section{REFERENCES}

Abolaffio M, Reynolds AM, Cecere JG, Paiva VH, Focardi S. 2018. Olfactory-cued navigation in shearwaters: linking movement patterns to mechanisms. Sci Rep. 8:11590.

Åkesson S, Alerstam T. 1998. Oceanic navigation: are there any feasible geomagnetic bicoordinate combinations for albatrosses? J Avian Biol. 29:618-625.

Baldaccini NE, Benvenuti S, Fiaschi V, Papi F. 1975. Pigeon navigation: effects of wind deflection, at home cage on homing behaviour. J Comp Physiol A. 99:177-186.

Benhamou S, Bried J, Bonadonna F, Jouventin P. 2003. Homing in pelagic birds: a pilot experiment with white-chinned petrels released in the open sea. Behav Process. 61:95-100.

Benvenuti S, Fiaschi V, Fiore L, Papi F. 1973. Homing performances of inexperienced and directionally trained pigeons subjected to olfactory nerve section. J Comp Physiol A. 83:8192.

Benvenuti S, Ioalè P, Gagliardo A, Bonadonna F. 1992. Effects of Zinc Sulfate-Induced anosmia on homing behavior of pigeons. Comp Biochem Physiol A. 103:519-526. 
Benvenuti S, Ioalè P, Massa B. 1993. Olfactory experiments on Cory's shearwater (Calonectris diomedea): The effect of intranasal zinc sulphate treatment on short-range homing behaviour. Boll Zool. 60:207-210.

Benvenuti S, Wallraff HG. 1985. Pigeon navigation: site simulation by means of atmospheric odours. J Comp Physiol A. 156:737-746.

Berthold P. 1991. Spatiotemporal programmes and genetics of orientation. In: Berthold P, editor. Orientation in birds. Berlin: Birkhauser Verlag; p. 86-105.

Berthold P, Gwinner E. 2002. Avian migration. Heidelberg (Germany): Springer-Verlag.

Billings SM. 1968. Homing in Leach's petrel. Auk. 85:36-43.

Bingman VP, Mench J.A. 1990. Homing behavior of Hippocampus and Para-Hippocampus lesioned pigeons following short-distance releases. Behav Brain Res. 40:227-238.

Bonadonna F, Bajzak C, Benhamou S, Igloi K, Jouventin P, Lipp HP, Dell'Omo G. 2005. Orientation in the wandering albatross: interfering with magnetic perception does not affect orientation performance. Proc R Soc Lond B. 272:489-495.

Bonadonna F, Benhamou S, Jouventin P. 2003a. Orientation in "featureless" environments: the extreme case of pelagic birds. In: Berthold P, et al., editors. Avian migration. Berlin, Heidelberg (Germany): Springer; p. 367-377.

Bonadonna F, Bretagnolle V. 2002. Smelling home: a good solution for burrow-finding in nocturnal petrels? J Exp Biol. 205:2519-2523.

Bonadonna F, Chamaille-Jammes S, Pinaud D, Weimerskirch H. 2003b. Magnetic cues: are they important in Black-browed Albatross Diomedea melanophris orientation? Ibis. 145:152155.

Bonadonna F, Spaggiari J, Weimerskirch H. 2001. Could osmotaxis explain the ability of blue petrels to return to their burrows at night? J Exp Biol. 204:1485-1489. 
Boström JE, Åkesson S, Alerstam T. 2012. Where on earth can animals use a geomagnetic bicoordinate map for navigation? Ecography. 35:1039-1047.

Bouchard B, Barnagaud JY, Poupard M, Glotin H, Gauffier P, Ortiz ST, Lisney TJ, Campagna S, Rasmussen M, Celerier A. 2019. Behavioural responses of humpback whales to food-related chemical stimuli. PLoS ONE. 14:e0212515.

Bramanti M, Dall'Antonia P, Papi F. 1988. A new technique to monitor the flight paths of birds. J Exp Biol. 134:467-472.

Cancalon P. 1982. Degeneration and regeneration of olfactory cells induced by $\mathrm{ZnSO}_{4}$ and other chemicals. Tissue Cell. 14:717-733.

Culik B, Hennicke J, Martin T. 2000. Humboldt penguins outmanoeuvring El Niño. J Exp Biol. 203:2311-2322.

Cunningham GB, Leclaire S, Toscani C, Bonadonna F. 2017. Responses of king penguin Aptenodytes patagonicus adults and chicks to two food-related odours. J Avian Biol. 48:235242.

Dall'Antonia P, Dall'Antonia L, Ribolini A, Ioalè P, Benvenuti S. 1999. Pigeon homing: site simulation experiments with birdborne direction recorders. Behav Process. 44:331-339.

Dell'Ariccia G, Bonadonna F. 2013. Back home at night or out until morning? Nycthemeral variations in homing of anosmic Cory's shearwaters in a diurnal colony. J Exp Biol. 216:1430-1433.

Dell'Ariccia G, Celerier A, Gabirot M, Palmas P, Massa B, Bonadonna F. 2014. Olfactory foraging in temperate waters: sensitivity to dimethylsulphide of shearwaters in the Atlantic Ocean and Mediterranean Sea. J Exp Biol. 217:1701-1709.

Fiaschi V, Baldaccini NE, Ioalè P, Papi F. 1981. Helicopter observations of homing in pigeons with biased orientation because of deflected winds at the home loft. Monitore Zool Ital. (N.S.) 15:139-153. 
Fiaschi V, Farina A, Ioalè P. 1974. Homing experiments on Swifts Apus apus (L.) deprived of olfactory perception. Monitore Zool Ital. (N.S.) 8:235-244.

Fleissner G, Holtkamp-Rotzler E, Hanzlik M, Winklhofer M, Fleissner G, Petersen N, Wiltschko W. 2003. Ultrastructural analysis of a putative magnetoreceptor in the beak of homing pigeons. J Comp Neurol. 458:350-360.

Füller E, Kowalski U, Wiltschko R. 1983. Orientation of homing pigeons: compass orientation vs piloting by landmarks. J Comp Physiol A. 153:55-58.

Gagliardo A. 2013. Forty years of olfactory navigation in birds. J Exp Biol. 216:2165-171.

Gagliardo A, Bried J, Lambardi P, Luschi P, Wikelski M, Bonadonna F. 2013. Oceanic navigation in Cory's shearwaters: evidence for a crucial role of olfactory cues for homing after displacement. J Exp Biol. 216:2798-2805.

Gagliardo A, Ioalè P, Filannino C, Wikelski M. 2011. Homing pigeons only navigate in air with Intact environmental odours: a test of the olfactory activation hypothesis with GPS data loggers. PLoS ONE. 6:e22385.

Gagliardo A, Ioalè P, Odetti F, Bingman VP. 2001. The ontogeny of the homing pigeon navigational map: evidence for a sensitive learning period. Proc R Soc Lond B. 268:197-202.

Gagliardo A, Ioalè P, Savini M, Wild JM. 2006. Having the nerve to home: trigeminal magnetoreceptor versus olfactory mediation of homing in pigeons. J Exp Biol. 209:28882892.

Gagliardo A, Ioalè P, Savini M, Wild M. 2008. Navigational abilities of homing pigeons deprived of olfactory or trigeminally mediated magnetic information when young. J Exp Biol. 211:2046-2051.

Gagliardo A, Ioalè P, Savini M, Wild M. 2009. Navigational abilities of adult and experienced homing pigeons deprived of olfactory or trigeminally mediated magnetic information. J Exp Biol. 212:3119-3124. 
Gagliardo A, Pollonara E, Wikelski M. 2016. Pigeon navigation: exposure to environmental odours prior to release is sufficient for homeward orientation, but not for homing. J Exp Biol. 219:2475-2480.

Gagliardo A, Pollonara E, Wikelski M. 2018. Only natural local odours allow homeward orientation in homing pigeons released at unfamiliar sites. J Comp Physiol A. 204:761-771.

Gagliardo A, Pollonara E, Wikelski M. 2020. Pigeons remember visual landmarks after one release and rely upon them more if they are anosmic. Anim Behav. 166:85-94.

Griffin DR. 1940. Homing experiments with Leach's petrels. Auk. 57:61-74.

Griffin DR. 1952a. Airplane observations of homing pigeons. Bull Mus Comp Zool. 107:411440.

Griffin DR. 1952b. Bird navigation. Biol Rev Camb Philos Soc. 27:359-400.

Grubb TC. 1972. Smell and foraging in shearwaters and petrels. Nature. 237:404-405.

Guilford T, Åkesson S, Gagliardo A, Holland RA, Mouritsen H, Muheim R, Wiltschko R, Wiltschko W, Bingman VP. 2011. Migratory navigation in birds: new opportunities in an era of fast-developing tracking technology. J Exp Biol. 214:3705-3712.

Guilford T, Biro D. 2014. Route following and the pigeon's familiar area map. J Exp Biol. 217:169-179.

Guilford T, Gagliardo A, Chappell J, Bonadonna F, de Perera TB, Holland R. 1998. Homing pigeons use olfactory cues for navigation in England. J Exp Biol. 201:895-900.

Hitchcock HB. 1952. Airplane observations of homing pigeons. Proc Am Phil Soc. 96:270289.

Hitchcock HB. 1955. Homing flights and orientation in pigeons. Auk. 72:355-373.

Holland RA, Thorup K, Gagliardo A, Bisson IA, Knecht E, Mizrahi D, Wikelski M. 2009. Testing the role of sensory systems in the migratory heading of a songbird. J Exp Biol. 212:4065-4071. 
Ioalè P. 1980. Further investigations on the homing behaviour of pigeon subjected to reverse wind direction at the loft. Monitore Zool Ital. (N.S.) 14:77-87.

Ioalè P. 1995. Preferred compass directions of homing pigeons in Italy. Boll Zool. 62:13-21. Ioalè P, Papi F, Fiaschi V, Baldaccini NE. 1978. Pigeon navigation: effects upon homing behaviour by reversing wind direction at the loft. J Comp Physiol A. 128:285-295.

Jorge PE, Marques PAM, Phillips JB. 2010. Activational effects of odours on avian navigation. Proc R Soc Lond B. 277:45-49.

Keeton WT. 1971. Magnets interfere with pigeon homing. PNAS. 68:102-106.

Kenyon KW, Rice DW. 1958. Homing of Laysan albatrosses. Condor. 60:3-6.

Kishkinev D, Anashina A, Ishchenko I, Holland RA. 2020. Anosmic migrating songbirds demonstrate a compensatory response following long-distance translocation: a radio-tracking study. J Ornithol. 161:47-57.

Kishkinev D, Chernetsov N, Heyers D, Mouritsen H. 2013. Migratory reed warblers need intact trigeminal nerves to correct for a 1,000 km Eastward displacement. PLoS ONE. 8:e65847.

Kishkinev D, Chernetsov N, Pakhomov A, Heyers D, Mouritsen H. 2015. Eurasian reed warblers compensate for virtual magnetic displacement. Curr Biol. 25:R822-R24.

Kishkinev D, Heyers D, Woodworth BK, Mitchell GW, Hobson KA, Norris DR. 2016. Experienced migratory songbirds do not display goal-ward orientation after release following a cross-continental displacement: an automated telemetry study. Sci Rep. 6:37326.

Levi WM. 1965. The pigeon. Columbia (SC): Bryan.

Luschi P, Dall'Antonia P. 1993. Anosmic pigeons orient from familiar sites by relying on the map-and-compass mechanism. Anim Behav. 46:1195-1203.

Massa B, Benvenuti S, Ioalè P, Lo Valvo M, Papi F. 1991. Homing of Cory's shearwaters (Calonectris diomedea) carrying magnets. Boll Zool. 58:245-247. 
Matthews GVT. 1951. The experimental investigation of navigation in homing pigeons. J Exp Biol. 28:508-536.

Matthews GVT. 1953. Navigation in the Manx shearwater. J Exp Biol. 30:370-396.

Matthews GVT. 1964. Individual experience as a factor in the navigation of Manx shearwaters. Auk. 81:132-146.

Michener MC, Walcott C. 1966. Navigation of single homing pigeons: Airplane observations by radio tracking. Science. 154:410-413.

Mora CV, Davison M, Wild JM, Walker MM. 2004. Magnetoreception and its trigeminal mediation in the homing pigeon. Nature. 432:508-511.

Mouritsen H, Huyvaert KP, Frost BJ, Anderson DJ. 2003. Waved albatrosses can navigate with strong magnets attached to their head. J Exp Biol. 206:4155-4166.

Nevitt GA, Bonadonna F. 2005. Sensitivity to dimethyl sulphide suggests a mechanism for olfactory navigation by seabirds. Biol Lett. 1:303-305.

Nevitt GA, Veit RR, Kareiva P. 1995. Dimethyl sulphide as a foraging cue for Antarctic procellariiform seabirds. Nature. 376:680-682.

Odetti F, Ioalè P, Gagliardo A. 2003. Development of the navigational map in homing pigeons: effects of flight experience on orientation performance. Anim Behav. 66:1093-1099. Padget O, Dell'Ariccia G, Gagliardo A, Gonzalez-Solis J, Guilford T. 2017. Anosmia impairs homing orientation but not foraging behaviour in free-ranging shearwaters. Sci Rep. 7:9668. Papi F. 1990. Olfactory navigation in birds. Experientia. 46:352-363.

Papi F, Fiore L, Fiaschi V, Benvenuti S. 1971. The influence of olfactory nerve section on the homing capacity of carrier pigeons. Monitore Zool Ital. (N.S.) 5:265-267.

Papi F, Fiore L, Fiaschi V, Benvenuti S. 1972. Olfaction and homing in pigeons. Monitore Zool Ital. (N.S.) 6:85-95. 
Papi F, Pardi L. 1968. The initial orientation of homing pigeons observed by radar. Monitore Zool Ital. 2:87-93.

Perdeck AC. 1958. Two types of orientation in migrating starlings, Sturnus vulgaris L., and chaffinches, Fringilla coelebs L., as revealed by displacement experiments. Ardea. 46:1-37.

Pollonara E, Luschi P, Guilford T, Wikelski M, Bonadonna F, Gagliardo A. 2015. Olfaction and topography, but not magnetic cues, control navigation in a pelagic seabird: displacements with shearwaters in the Mediterranean Sea. Sci Rep. 5:16486.

Reynolds AM, Cecere JG, Paiva VH, Ramos JA, Focardi S. 2015. Pelagic seabird flight patterns are consistent with a reliance on olfactory maps for oceanic navigation. Proc R Soc Lond B. 282:20150468.

Roper TJ. 1999. Olfaction in birds. Adv Stud Behav. 28:247-332.

Safi K, Gagliardo A, Wikelski M, Kranstauber B. 2016. How displaced migratory birds could use volatile atmospheric compounds to find their migratory corridor: A test using a particle dispersion model. Front Behav Neurosci. 10:175.

Schmidt-Koenig K. 1979. Avian orientation and navigation. London: Academic Press.

Schmidt-Koenig K, Walcott C. 1978. Tracks of pigeons homing with frosted lenses. Anim Behav. 26:480-486.

Teyssèdre A. 1986. Radio-tracking of pigeons previously exposed to random oscillating magnetic fields. Behaviour. 96:265-276.

Thorup K, Bisson IA, Bowlin MS, Holland RA, Wingfield JC, Ramenofsky M, Wikelski M. 2007. Evidence for a navigational map stretching across the continental US in a migratory songbird. PNAS. 104:18115-18119.

Thorup K, Vega ML, Snell KRS, Lubkovskaia R, Willemoes M, Sjoberg S, Sokolov LV, Bulyuk V. 2020. Flying on their own wings: young and adult cuckoos respond similarly to long-distance displacement during migration. Sci Rep. 10:7698. 
Treiber CD, Salzer MC, Riegler J, Edelman N, Sugar C, Breuss M, Pichler P, Cadiou H, Saunders M, Lythgoe M, et al. 2012. Clusters of iron-rich cells in the upper beak of pigeons are macrophages not magnetosensitive neurons. Nature. 484:367-370.

Walcott C. 1996. Pigeon homing: observations, experiments and confusions. J Exp Biol. 199:21-27.

Walcott C, Wiltschko W, Wiltschko R, Zupanc GKH. 2018. Olfactory navigation versus olfactory activation: a controversy revisited. J Comp Physiol A. 204:703-7o6.

Wallraff HG. 1966. Über die Heimfindeleistungen von Brieftauben nach Haltungverschiedenartig abgeschirmten Volieren [About the home-finding performance of carrier pigeons in aviaries which are screened in different ways]. Z Vergl Physiol. 52:215259. German.

Wallraff HG. 1970. Further Aviary Experiments with Homing Pigeons: Probable Influence of Dynamic Factors of the Atmosphere on their Orientation. Z Vergl Physiol. 68:182-201. German.

Wallraff HG. 1978. Preferred compass directions in initial orientation of homing pigeons. In: Schmidt-Koenig K, Keeton WT, editors. Animal migration, navigation and homing Heidelberg (Germany): Springer Verlag; p. 171-183.

Wallraff HG. 1981. The olfactory component of pigeon navigation: steps of analysis. J Comp Physiol A. 143:411-422.

Wallraff HG. 2000. Simulated navigation based on observed gradients of atmospheric trace gases (models on pigeon homing, Part 3). J Theor Biol. 205:133-145.

Wallraff HG. 2004. Avian olfactory navigation: its empirical foundation and conceptual state. Anim Behav. 67:189-204.

Wallraff HG. 2005. Avian navigation: Pigeon homing as a paradigm. Heidelberg (Germany): Springer Verlag. 
Wallraff HG, Andreae MO. 2000. Spatial gradients in ratios of atmospheric trace gases: a study stimulated by experiments on bird navigation. Tellus B Chem Phys Meteorol. 52:11381156.

Wallraff HG, Kiepenheuer J, Neumann MF, Streng A. 1995. Homing experiments with starlings deprived of the sense of smell. Condor. 97:20-26.

Wallraff HG, Neumann MF. 1989. Contribution of olfactory navigation and non-olfactory pilotage to pigeon homing. Behav Ecol Sociobiol. 25:293-302.

Wikelski M, Arriero E, Gagliardo A, Holland RA, Huttunen MJ, Juvaste R, Mueller I, Tertitski G, Thorup K, Wild M, et al. 2015. True navigation in migrating gulls requires intact olfactory nerves. Sci Rep. 24(5):17061.

Wiltschko R. 1991. The role of experience in avian navigation and homing. In: Berthold P, editor. Orientation in birds. Basel: Birkhauser; p. 250-269.

Wiltschko R. 1996. The function of olfactory input in pigeon orientation: does it provide navigational information or play another role? J Exp Biol. 199:113-119.

Wiltschko R, Siegmund B, Stapput K. 2005. Navigational strategies of homing pigeons at familiar sites: do landmarks reduce the deflections induced by clock-shifting? Behav Ecol Sociobiol. 59:303-312.

Wiltschko R, Wiltschko W. 1998. Pigeon homing: Effect of various wavelengths of light during displacement. Naturwissenschaften. 85:164-167.

Wright KLB, Pichegru L, Ryan PG. 2011. Penguins are attracted to dimethyl sulphide at sea. J Exp Biol. 214:2509-2511.

Wynn J, Padget O, Mouritsen H, Perrins C, Guilford FT. 2020. Natal imprinting to the Earth's magnetic field in a pelagic seabird. Curr Biol. 30:1-5. 
Zannoni N, Wikelski M, Gagliardo A, Raza A, Kramer S, Seghetti C, Wang N, Edtbauer A, Williams J. 2020. Identifying volatile organic compounds used for olfactory navigation by homing pigeons. Sci Rep. 10:15879. 